\title{
The Effect of IGF2BP2 Gene Polymorphisms on Pioglitazone Response in Chinese Type 2 Diabetes Patients
}

\author{
Liu-Fu Zhang $^{\mathrm{a}}$ Qi Pei ${ }^{\mathrm{c}}$ Guo-Ping Yang ${ }^{\mathrm{c}}$ Ying-Chun Zhao $^{\mathrm{d}}$ Yan-Fang Mu ${ }^{\mathrm{a}}$ \\ Qiong Huang ${ }^{b}$ You-Ling Zhu ${ }^{a}$
}

\begin{abstract}
${ }^{a}$ Department of Neurology, Hefei Binhu Hospital, Hefei First People's Hospital, and ${ }^{b}$ Institute of Clinical Pharmacology, Anhui Medical University, Key Laboratory of Anti-Inflammatory and Immune Medicine, Ministry of Education, Hefei, and ' Department of Pharmacy, The Third Xiangya Hospital, Central South University, Changsha, PR China; ${ }^{d}$ Osteoporosis Research Center, Creighton University, Omaha, Nebr., USA
\end{abstract}

\section{Key Words}

IGF2BP2 rs1470579 - IGF2BP2 rs4402960 - Genetic

polymorphisms - Type 2 diabetes mellitus · Pioglitazone .

Therapeutic efficacy

\begin{abstract}
Background: Genome-wide association studies identified that insulin-like growth factor 2 mRNA-binding protein 2 (IGF2BP2) genetic polymorphisms are related to type 2 diabetes mellitus (T2DM) in several populations. This study aimed to investigate whether the IGF2BP2 gene rs 1470579 and rs4402960 polymorphisms were associated with T2DM and pioglitazone efficacy in Chinese T2DM patients. Methods: A total of 281 T2DM patients and 111 healthy volunteers were enrolled to identify the IGF2BP2 gene rs 1470579 and rs4402960 polymorphisms; 86 patients were randomly selected and given a 12-week pioglitazone treatment (30 mg/ day). Fasting plasma glucose, postprandial plasma glucose (PPG), glycated hemoglobin, serum triglycerides (TG), total cholesterol, low-density lipoprotein cholesterol and highdensity lipoprotein cholesterol $(\mathrm{HDL}-\mathrm{C})$ were determined before and after pioglitazone treatment. Results: The results showed that the IGF2BP2 gene rs 1470579 and rs4402960 polymorphisms were associated with T2DM in a Chinese
\end{abstract}

population $(\mathrm{OR}=2.002,95 \% \mathrm{Cl} 1.170-3.426, \mathrm{p}<0.05 ; \mathrm{OR}=$ $1.879,95 \% \mathrm{Cl} 1.110-3.182, \mathrm{p}<0.05)$. The effect of pioglitazone on PPG $(p<0.05)$, TG $(p<0.01)$ and HDL-C $(p<0.05)$ was lower in patients with the rs $1470579 \mathrm{AC}+\mathrm{CC}$ genotypes than in AA genotype carriers. Its effect on PPG level was also lower in patients with the GT+TT genotypes of rs 4402960 than in patients with the GG genotype $(p<0.05)$. Conclusions: The IGF2BP2 gene rs 1470579 and rs 4402960 polymorphisms were associated with T2DM and therapeutic efficacy of pioglitazone in this Chinese population.

(c) 2014 S. Karger AG, Basel

\section{Introduction}

Diabetes mellitus is a kind of metabolic disease which is characterized by high blood sugar. Around the globe, there were 366 million diabetes patients in 2011, and it is estimated that there will be 552 million patients in 2030 [1]. Type 2 diabetes mellitus (T2DM) accounts for 90 $95 \%$ of new-onset diabetes annually [2]. The development of T2DM is influenced by genetic components and

Chinese Clinical Trial Registration No. ChiCTR-CCC00000406.

\begin{tabular}{ll}
\hline KARGER & $\begin{array}{l}\text { ○ 2014 S. Karger AG, Basel } \\
0031-7012 / 14 / 0944-0115 \$ 39.50 / 0 \quad \text { Karger }\end{array}$ \\
E-Mail karger@karger.com & $\begin{array}{l}\text { This is an Open Access article licensed under the terms of the } \\
\text { Creative Commons Attribution-NonCommercial 3.0 Un- } \\
\text { ported license (CC BY-NC) (www.karger.com/OA-license), } \\
\text { applicable to the online version of the article only. Distribu- } \\
\text { tion permitted for non-commercial purposes only. }\end{array}$
\end{tabular}

Prof. Qiong Huang

Institute of Clinical Pharmacology, Anhui Medical University

Key Laboratory of Anti-Inflammatory and Immune Medicine, Ministry of Education

Hefei, Anhui 230032 (PR China)

E-Mail qionghuang@126.com 
environmental factors [3-5]. Genetic studies such as high-throughput technology genome-wide association studies have identified some new loci related to T2DM in recent years [6-11]. It has been proved that the insulinlike growth factor $2 \mathrm{mRNA}$-binding protein 2 (IGF2BP2) gene rs 1470579 and rs4402960 polymorphisms [6] are associated with susceptibility to and the development of T2DM. This association was also replicated in Asian populations [7-9].

IGF2BP2 is an mRNA-binding protein which is involved in RNA location, stability and translation [10]. IGF2BP2 regulates insulin-like growth factor 2 (IGF2) translation by binding to the $5^{\prime}$ UTR of the IGF2 mRNA. IGF2 also plays an important role in the growth and insulin signaling pathways [11]. IGF2BP2 gene rs1470579and rs4402960-mutated carriers showed a moderately increased risk of T2DM in genome-wide association study results. T2DM patients with different IGF2BP2 genotypes showed various levels of insulin secretion. It has been demonstrated that variants in the IGF2BP2 gene affect first-phase insulin secretion and the disposition index detected by hyperglycemic clamps [12].

Thiazolidinediones (TZD) are insulin-sensitizing agents which could decrease fasting plasma glucose (FPG) and postprandial plasma glucose (PPG) levels by increasing glucose uptake in the peripheral tissue [2]. Pioglitazone is a new TZD, and the only available one which has been widely used for T2DM therapy $[13,14]$. The therapeutic efficacy of pioglitazone showed individual differences. It has been proved that T2DM patients with different peroxisome proliferator-activated receptor- $\gamma$ [15] or resistin [16] genotypes showed distinctive effects in multiple-dose pioglitazone therapy.

In this study, we intended to investigate the effect of the IGF2BP2 gene rs1470579 and rs4402960 polymorphisms on the therapeutic efficacy of pioglitazone in Chinese T2DM patients.

\section{Subjects and Methods}

\section{Subjects}

The study group included 281 unrelated T2DM patients from the First and Third Affiliated Hospitals of the Anhui Medical University and 111 unrelated normoglycemic control subjects from the First Affiliated Hospital of the Anhui Medical University. The inclusion criteria were as follows: (1) T2DM was diagnosed in accordance with World Health Organization criteria in 1999 (FPG $\geq 7.0 \mathrm{mmol} / 1$ or 2 -hour PPG $\geq 11.1 \mathrm{mmol} / \mathrm{l}$ ); (2) body mass index (BMI) between 19 and 30; (3) no prior TZD use, and (4) no change in medication in the previous 3 months. Normoglycemic control subjects were selected by an FPG $<6.1 \mathrm{mmol} / \mathrm{l}$ and a 2-hour PPG
$<7.8 \mathrm{mmol} / \mathrm{l}$. The exclusion criteria were as follows: (1) type $1 \mathrm{dia}-$ betes mellitus; (2) ischemic heart disease, congestive heart failure, kidney or liver diseases; (3) insulin treatment or other drugs which affect the glucose metabolism (such as glucocorticoids), and (4) pregnancy or lactation in women.

A total of 86 T2DM patients, who received a daily dose of 30 mg oral pioglitazone (Kasiping, Hangzhou, China) for 12 consecutive weeks, were recruited from the Third Xiangya Hospital of the Central South University and the Third Affiliated Hospital of the Anhui Medical University. These patients were advised to maintain the same levels of energy intake and physical activity. The local ethics committee approved the protocol, and all subjects signed the informed consent form before the study started. We also applied for clinical admission to the Chinese Clinical Trial Register (No. ChiCTR-RNC-12001949).

\section{Clinical Measurements}

Venous blood samples of the subjects were collected in the fasting state and $2 \mathrm{~h}$ after a standardized breakfast at week 0 and week 12 (the end of administration). The BMI was calculated as the weight in kilograms divided by body height in meters squared. Concentrations of FPG, total cholesterol (TC) and triglyceride (TG) were determined by enzymatic colorimetric assay. The highdensity lipoprotein cholesterol (HDL-C) concentration was measured by lipoprotein electrophoresis. The low-density lipoprotein cholesterol (LDL-C) concentration was calculated according to the Friedewald formula [17]. Plasma $\mathrm{HbA}_{1 \mathrm{c}}$ levels were measured by high-performance liquid chromatography assay.

\section{Genotyping}

Genomic DNA was isolated from peripheral blood leukocytes using the Promega DNA Purification Kit (Promega, USA). The IGF2BP2 gene rs4402960 and rs1470579 polymorphisms were genotyped using the polymerase chain reaction-restriction fragment length polymorphism method. All the primers and reagents were previously described [9].

\section{Statistical Analysis}

All analyses were performed with SPSS software (version 17.0 for Windows; SPSS Inc., Chicago, Ill., USA). Measurement data are expressed as means \pm SD $(95 \% \mathrm{CI})$. The Hardy-Weinberg equilibrium and frequencies were assessed with a Pearson $\chi^{2}$ test. Continuous variables were compared using Student's t test between the T2DM and control groups. Nonnormally distributed data were analyzed by the Mann-Whitney test. OR were calculated using a logistic regression analysis while adjusting for BMI, TG and LDL. Differences between before and after pioglitazone treatment were analyzed by paired t tests. Statistical power was calculated by the power calculator software PASS (www.ncss.com). A p value $<0.05$ was considered to be statistically significant.

\section{Results}

The IGF2BP2 Gene rs 1470579 and $r s 4402960$

Polymorphisms Were Associated with T2DM

We conducted a case-control study to detect whether the rs1470579 and rs4402960 polymorphisms of the 
Table 1. Association study of two IGF2BP2 gene polymorphisms and T2DM

\begin{tabular}{|c|c|c|c|c|c|c|}
\hline & \multirow{2}{*}{$\begin{array}{l}\text { Subjects, } \\
\mathrm{n}(\%)\end{array}$} & \multirow[t]{2}{*}{$\mathrm{p}^{\mathrm{a}}$} & \multicolumn{2}{|l|}{ Univariate analysis } & \multicolumn{2}{|l|}{ Multivariate analysis } \\
\hline & & & OR (95\% CI) & $\mathrm{p}^{\mathrm{b}}$ & OR $(95 \% \mathrm{CI})$ & $\mathrm{p}^{\mathrm{c}}$ \\
\hline \multicolumn{7}{|l|}{ T2DM patient group } \\
\hline rs1470579 AA & $143(50.89)$ & & & & & \\
\hline rs1470579 AC+CC & $138(49.11)$ & & & & & \\
\hline \multicolumn{7}{|l|}{ Healthy control group } \\
\hline rs 1470579 AA & $67(60.36)$ & & 1.00 (reference) & & 1.00 (reference) & \\
\hline rs1470579 AC+CC & $44(39.64)$ & 0.090 & $1.616(1.046-2.497)$ & 0.031 & $2.002(1.170-3.426)$ & 0.011 \\
\hline \multicolumn{7}{|l|}{ T2DM patient group } \\
\hline rs4402960 GG & $136(48.40)$ & & & & & \\
\hline rs4402960 GT+TT & $145(51.60)$ & & & & & \\
\hline \multicolumn{7}{|l|}{ Healthy control group } \\
\hline rs4402960 GG & $69(62.16)$ & & 1.00 (reference) & & 1.00 (reference) & \\
\hline rs4402960 GT+TT & $42(37.84)$ & 0.014 & $1.650(1.046-2.602)$ & 0.031 & $1.879(1.110-3.182)$ & 0.019 \\
\hline
\end{tabular}

IGF2BP2 gene were associated with T2DM. A total of 281 unrelated T2DM patients and 111 healthy controls were genotyped. The genotypic distributions of the two polymorphisms were in agreement with the Hardy-Weinberg equilibrium $(p>0.05)$. Considering that the frequency of the mutated homozygous genotype was limited, we thus applied a recessive model in this analysis. The recessive model showed that the rs1470579 genotype was significantly associated with T2DM and C allele carriers had a relative risk of 1.616 (95\% CI 1.046-2.497). The G allelic frequency of the rs4402960 polymorphism in T2DM patients was obviously higher than that in healthy controls $(\mathrm{p}<0.05)$. The rs4402960 genotype was also significantly associated with $\mathrm{T} 2 \mathrm{DM}$, and $\mathrm{T}$ allele carriers had a relative risk of 1.650 (95\% CI 1.046-2.602). After adjustment for BMI, TG and LDL, both polymorphisms showed to be correlated with T2DM $(\mathrm{OR}=2.002$, 95\% CI 1.170-3.426, for $\mathrm{rs} 1470579$; OR $=1.879,95 \%$ CI $1.110-3.182$, for rs4402960; table 1).

\section{Comparisons of Baseline Blood Characteristics}

between T2DM Patients with Different Genotypes

The baseline clinical characteristics of all T2DM patients with different rs1470579 and rs4402960 genotypes are summarized in table 2 . There were no significant differences in sex composition, age or BMI between differ- ent genotypic groups. We found that patients with the $\mathrm{C}$ allele of rs1470579 had higher FPG (9.58 \pm 3.49 vs. $8.84 \pm$ $3.71 \mathrm{mmol} / \mathrm{l}, \mathrm{p}<0.05)$ and PPG $(16.73 \pm 6.28$ vs. $15.09 \pm$ $5.54 \mathrm{mmol} / \mathrm{l}, \mathrm{p}<0.05)$ levels than AA genotype carriers (table 2; fig. 1). With regard to the rs4402960 polymorphism, we found that patients with the T allele had higher FPG $(10.21 \pm 4.04$ vs. $8.50 \pm 2.94 \mathrm{mmol} / \mathrm{l}, \mathrm{p}<0.01)$ and PPG $(17.20 \pm 6.63$ vs. $15.16 \pm 5.11 \mathrm{mmol} / \mathrm{l}, \mathrm{p}<0.05)$ levels than GG genotype carriers (table 2; fig. 2). Therefore, patients with a mutated IGF2BP2 gene rs1470579 or rs4402960 polymorphism showed worse blood glucose control.

\section{Changes in Blood Characteristics of T2DM Patients after Pioglitazone Treatment}

A total of 86 T2DM patients (48 male and 38 female) were treated daily with $30 \mathrm{mg}$ oral pioglitazone for 12 consecutive weeks. Pioglitazone significantly decreased the concentrations of FPG $(8.23 \pm 1.14$ vs. $7.01 \pm 1.04$ $\mathrm{mmol} / \mathrm{l}, \mathrm{p}<0.001), \mathrm{PPG}(12.62 \pm 2.84$ vs. $10.52 \pm 2.92$ $\mathrm{mmol} / \mathrm{l}, \mathrm{p}<0.001), \mathrm{HbA}_{\mathrm{lc}}(7.63 \pm 1.36$ vs. $6.68 \pm 0.93 \%$, $\mathrm{p}<0.001), \mathrm{TG}(2.27 \pm 2.35$ vs. $1.81 \pm 1.15 \mathrm{mmol} / \mathrm{l}, \mathrm{p}<$ $0.001)$ and TC ( $4.98 \pm 0.95$ vs. $4.70 \pm 0.80 \mathrm{mmol} / \mathrm{l}, \mathrm{p}<$ 0.05 ) in T2DM patients (table 3 ). 
Table 2. Baseline clinical and biochemical characteristics of the different genotypes of the IGF2BP2 gene in T2DM patients

\begin{tabular}{|c|c|c|c|c|c|c|}
\hline \multirow[t]{2}{*}{ Parameters } & \multicolumn{2}{|l|}{ rs1470579 genotypes } & \multirow[t]{2}{*}{$\mathrm{p}$} & \multicolumn{2}{|l|}{ rs4402960 genotypes } & \multirow[t]{2}{*}{$\mathrm{p}$} \\
\hline & $\overline{\mathrm{AA}}$ & $\mathrm{AC}+\mathrm{CC}$ & & $\overline{\mathrm{GG}}$ & $\mathrm{GT}+\mathrm{TT}$ & \\
\hline Number (M/F) & $143(72 / 71)$ & $138(66 / 72)$ & $0.716^{\mathrm{a}}$ & $136(66 / 70)$ & $145(72 / 73)$ & $0.850^{\mathrm{a}}$ \\
\hline Age, years & $50.51 \pm 10.33(48.77-52.25)$ & $52.12 \pm 10.99(50.14-54.09)$ & 0.226 & $50.82 \pm 10.79(49.06-52.59)$ & $51.81 \pm 11.25(49.76-53.86)$ & 0.467 \\
\hline BMI & $25.69 \pm 3.39(25.11-26.27)$ & $25.38 \pm 3.62(24.72-26.04)$ & 0.479 & $25.81 \pm 3.44(25.12-26.27)$ & $25.83 \pm 3.40(25.20-26.45)$ & 0.747 \\
\hline $\mathrm{FPG}, \mathrm{mmol} / \mathrm{l}$ & $8.84 \pm 3.71(8.24-9.44)$ & $9.58 \pm 3.49(9.03-10.12)$ & $0.021^{*, \mathrm{~b}}$ & $8.50 \pm 2.94(7.99-9.02)$ & $10.21 \pm 4.04(9.54-10.88)$ & $0.002^{* *, \mathrm{~b}}$ \\
\hline $\mathrm{PPG}, \mathrm{mmol} / \mathrm{l}$ & $15.09 \pm 5.54(14.15-16.02)$ & $16.73 \pm 6.28(15.72-17.75)$ & $0.025^{\mathrm{b}}$ & $15.16 \pm 5.11(14.22-16.09)$ & $17.20 \pm 6.63(16.07-18.33)$ & $0.018^{*, \mathrm{~b}}$ \\
\hline $\mathrm{HbA}_{1 \mathrm{c}}, \%$ & $9.33 \pm 6.13(8.26-10.40)$ & $8.65 \pm 2.49(8.23-9.08)$ & 0.235 & $9.18 \pm 6.38(8.00-10.37)$ & $8.98 \pm 2.65(8.51-9.44)$ & $0.623^{\mathrm{b}}$ \\
\hline $\mathrm{TG}, \mathrm{mmol} / \mathrm{l}$ & $3.39 \pm 3.59(2.75-4.04)$ & $2.71 \pm 2.29(2.27-3.15)$ & $0.237^{\mathrm{b}}$ & $3.28 \pm 3.66(2.63-3.93)$ & $2.74 \pm 2.10(2.34-3.15)$ & $0.722^{\mathrm{b}}$ \\
\hline $\mathrm{TC}, \mathrm{mmol} / \mathrm{l}$ & $4.99 \pm 1.96(4.66-5.32)$ & $4.95 \pm 1.53(4.68-5.21)$ & 0.833 & $5.04 \pm 2.06(4.67-5.42)$ & $4.92 \pm 1.48(4.66-5.19)$ & $0.525^{\mathrm{b}}$ \\
\hline $\mathrm{HDL}-\mathrm{C}, \mathrm{mmol} / \mathrm{l}$ & $1.47 \pm 1.02(1.28-1.65)$ & $1.32 \pm 0.56(1.21-1.43)$ & $0.519^{\mathrm{b}}$ & $1.40 \pm 1.10(1.20-1.60)$ & $1.30 \pm 0.57(1.17-1.41)$ & $0.980^{\mathrm{b}}$ \\
\hline LDL-C, mmol/l & $2.72 \pm 0.99(2.54-2.90)$ & $2.78 \pm 1.23(2.58-2.97)$ & 0.657 & $2.83 \pm 1.00(2.64-3.03)$ & $2.68 \pm 1.15(2.47-2.88)$ & 0.282 \\
\hline
\end{tabular}

Data are given as means $\pm \mathrm{SD}$ with $95 \% \mathrm{CI}$ in parentheses unless specified otherwise. ${ }^{*} \mathrm{p}<0.05 ; * * \mathrm{p}<0.01$. $^{\text {a }} \mathrm{p}$ values represent the statistical difference between the $\mathrm{AA}$ and $\mathrm{AC}+\mathrm{CC}$ (GG and GT+TT) genotype groups and were assessed by the two-sample t test. ${ }^{b} \mathrm{p}$ values were determined by the Mann-Whitney test.

Fig. 1. Comparisons of the baseline levels of FPG (a) and PPG (b) in T2DM patients with different IGF2BP2 gene rs1470579 genotypes. Data are means $\pm \mathrm{SD} .{ }^{*} \mathrm{p}<0.05$ compared with the AA genotype $(n=281)$.

Fig. 2. Comparisons of the baseline levels of FPG (a) and PPG (b) in T2DM patients with different IGF2BP2 gene rs4402960 genotypes. Data are means $\pm \mathrm{SD}$. ${ }^{*} \mathrm{p}<0.05$, ** $\mathrm{p}<0.01$, compared with the GG genotype $(\mathrm{n}=281)$.
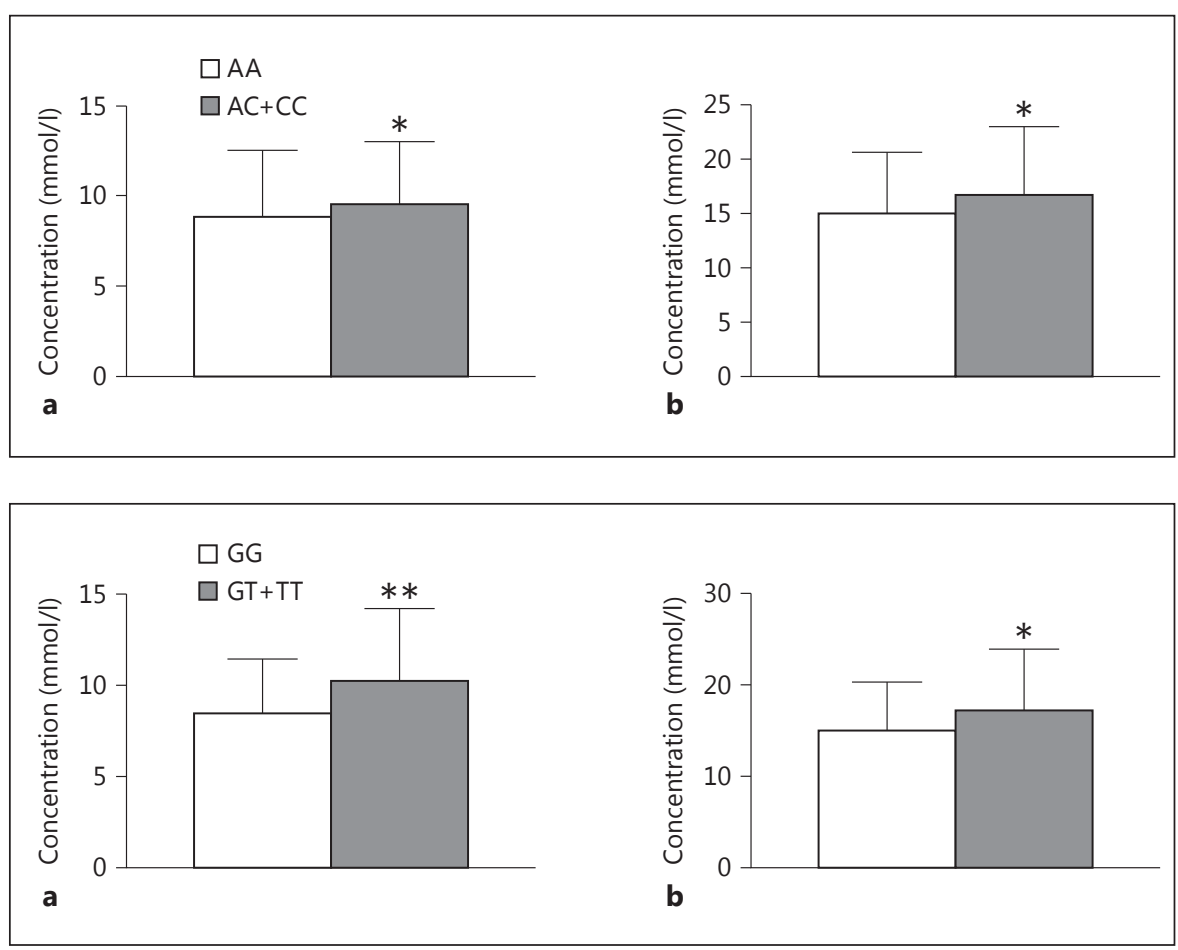

Influence of the IGF2BP2 Gene Polymorphisms on the Therapeutic Efficacy of Pioglitazone in T2DM Patients We analyzed all the differences between post- and pretreatment values (DV) between different IGF2BP2 genotypes. The effect of pioglitazone was significantly lower in patients with the IGF2BP2 gene rs1470579 AC+CC genotype with regard to PPG (DV $-1.07 \pm 4.04 \mathrm{mmol} / \mathrm{l})$, TG (DV $0.05 \pm 0.72 \mathrm{mmol} / \mathrm{l})$ and HDL-C (DV $-0.02 \pm 0.29$ $\mathrm{mmol} / \mathrm{l}$ ) compared with AA genotype carriers (DV for PPG: $-2.65 \pm 3.85 \mathrm{mmol} / \mathrm{l}, \mathrm{p}<0.05$; DV for TG: $-0.66 \pm$ 
Table 3. Clinical characteristics of all T2DM patients before and after pioglitazone treatment

\begin{tabular}{lccc}
\hline Parameters & Before & After & $\mathrm{p}$ \\
\hline FPG, mmol/l & $8.23 \pm 1.14(8.00-8.47)$ & $7.01 \pm 1.04(6.78-7.24)$ & $<0.000^{* *}$ \\
PPG, mmol/l & $12.62 \pm 2.84(11.99-13.25)$ & $10.52 \pm 2.92(19.87-11.16)$ & $<0.000^{* *}$ \\
$\mathrm{HbA}_{\mathrm{lc}}, \%$ & $7.63 \pm 1.36(7.33-7.93)$ & $6.68 \pm 0.93(6.47-6.88)$ & $<0.000^{* *}$ \\
TG, mmol/l & $2.27 \pm 2.35(1.75-2.79)$ & $1.81 \pm 1.15(1.56-2.07)$ & $0.003^{* *}$ \\
TC, mmol/l & $4.98 \pm 0.95(4.77-5.19)$ & $4.70 \pm 0.80(4.52-4.87)$ & $0.036^{*}$ \\
HDL-C, mmol/l & $1.10 \pm 0.31(1.03-1.17)$ & $1.12 \pm 0.37(1.03-1.21)$ & 0.252 \\
LDL-C, mmol/l & $2.89 \pm 0.80(2.71-3.06)$ & $2.73 \pm 0.73(2.57-2.89)$ & 0.082 \\
\hline
\end{tabular}

Data are given as means \pm SD with $95 \%$ CI in parentheses. $\mathrm{p}$ values were determined by the paired Student $\mathrm{t}$ test. ${ }^{*} \mathrm{p}<0.05 ; * * \mathrm{p}<0.01$.

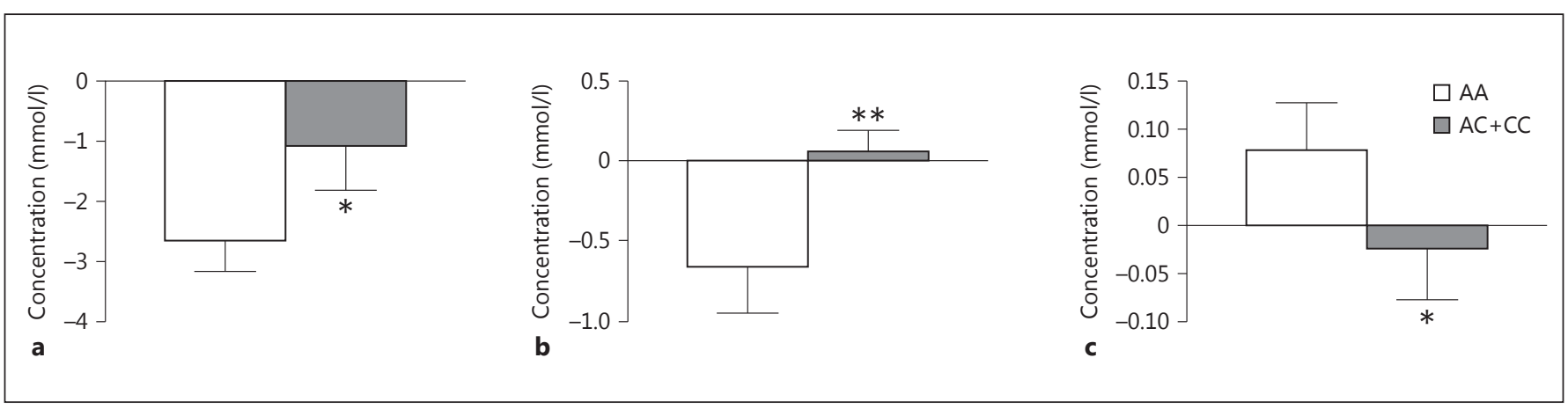

Fig. 3. Comparisons of the DV of PPG (a), TG (b) and HDL-C (c) between the AA genotype and the AC+CC genotypes of the IGF2BP2 gene rs1470579 polymorphism in T2DM patients. Data are means \pm SD. ${ }^{*} \mathrm{p}<0.05$, ${ }^{* *} \mathrm{p}<0.01$, compared with the AA genotype $(\mathrm{n}=86)$.

2.18, $\mathrm{p}<0.01 \mathrm{mmol} / \mathrm{l}$; DV for HDL-C: $0.08 \pm 0.38 \mathrm{mmol} / \mathrm{l}$, $\mathrm{p}<0.05$; table 4; fig. 3). Meanwhile, pioglitazone showed a lower effect in patients with the GT+TT genotypes of rs4402960 with regard to the PPG level (DV -0.70 \pm $3.92 \mathrm{mmol} / \mathrm{l}$ ) compared with GG genotype carriers (DV $-2.80 \pm 3.81 \mathrm{mmol} / \mathrm{l}, \mathrm{p}<0.05$; table 4 ; fig. 4).

\section{Discussion}

In the present study, we explored the effects of the IGF2BP2 gene rs1470579 and rs4402960 polymorphisms on pioglitazone response in Chinese T2DM patients. These polymorphisms have been shown to be associated with T2DM in several populations [18-20]. The relation between polymorphism rs1470579 and T2DM has been found in Japanese [8, 19], Israeli [21], Lebanese [22] and Tunisian Arabs [23]. Our results showed that the frequencies of different genotypes of polymorphism

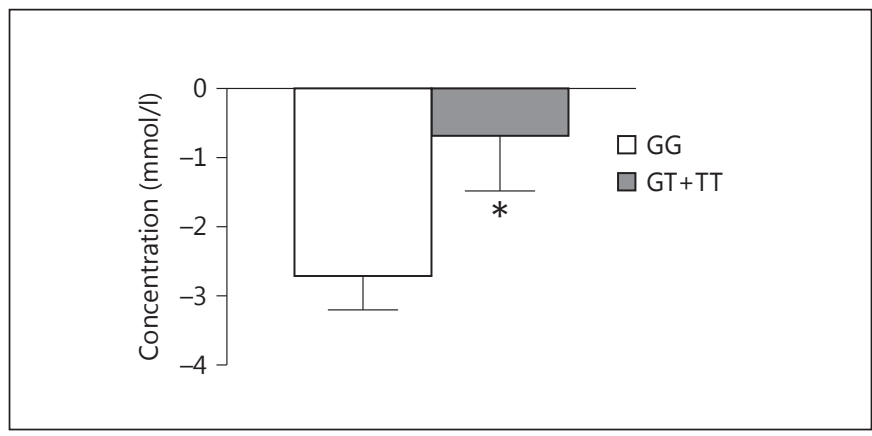

Fig. 4. Comparison of the DV of PPG between the GG genotype and the GT+TT genotypes of the IGF2BP2 gene rs4402960 polymorphism in T2DM patients. Data are means \pm SD. ${ }^{*} \mathrm{p}<0.05$ compared with the GG genotype $(n=86)$. 
Table 4. Comparisons of DV in T2DM patients with different rs1470579 and rs4402960 genotypes before and after pioglitazone treatment

\begin{tabular}{|c|c|c|c|c|c|c|}
\hline Parameters & \multicolumn{2}{|l|}{ rs1470579 genotype } & $\mathrm{p}$ & \multicolumn{2}{|l|}{ rs4402960 genotype } & $\mathrm{p}$ \\
\hline Number $(M / F)$ & $57(33 / 24)$ & $29(15 / 14)$ & $0.541^{\mathrm{a}}$ & $61(35 / 26)$ & $25(13 / 12)$ & $0.648^{\mathrm{a}}$ \\
\hline \multicolumn{7}{|l|}{ FPG, $\mathrm{mmol} / \mathrm{l}$} \\
\hline Baseline & $8.18 \pm 1.03(7.90-8.45)$ & $8.28 \pm 1.07(7.87-8.69)$ & 0.653 & $8.28 \pm 1.12(8.00-8.57)$ & $8.05 \pm 0.84(7.71-8.40)$ & 0.359 \\
\hline After treatment & $6.86 \pm 0.92(6.61-7.09)$ & $7.30 \pm 1.22(6.83-7.76)$ & 0.060 & $6.89 \pm 0.97(6.65-7.14)$ & $7.21 \pm 1.19(6.72-7.70)$ & 0.199 \\
\hline \multicolumn{7}{|l|}{$P P G, \mathrm{mmol} / \mathrm{l}$} \\
\hline Baseline & $12.91 \pm 2.86(12.16-13.66)$ & $12.20 \pm 3.23(10.97-13.43)$ & 0.300 & $13.11 \pm 3.21(12.29-13.93)$ & $11.72 \pm 2.11(10.85-12.59)$ & $0.049^{*}$ \\
\hline After treatment & $10.26 \pm 2.98(9.47-11.04)$ & $11.13 \pm 2.87(10.04-12.23)$ & 0.194 & $10.31 \pm 2.67(9.63-11.00)$ & $11.03 \pm 3.59(9.55-12.51)$ & 0.315 \\
\hline DV PPG & $-2.65 \pm 3.85(-3.66$ to -1.64$)$ & $-1.07 \pm 4.04(-2.60$ to 0.47$)$ & $0.031^{b}$ & $-2.80 \pm 3.81(-3.78$ to -1.82$)$ & $-0.70 \pm 3.92(-2.31$ to 0.92$)$ & $0.018^{*, \mathrm{~b}}$ \\
\hline \multicolumn{7}{|l|}{$H b A_{1}, \%$} \\
\hline Baseline & $7.63 \pm 1.44(7.26-8.01)$ & $7.72 \pm 1.39(7.25-8.30)$ & 0.671 & $7.56 \pm 1.47(7.19-7.94)$ & $7.85 \pm 1.18(7.37-8.34)$ & 0.383 \\
\hline Baseline & $2.40 \pm 2.64(1.70-3.09)$ & $1.81 \pm 1.25(1.34-2.29)$ & $0.989^{\mathrm{b}}$ & $2.30 \pm 2.60(1.64-2.97)$ & $2.00 \pm 1.31(1.46-2.54)$ & $0.812^{\mathrm{b}}$ \\
\hline After treatment & $1.74 \pm 1.10(1.45-2.02)$ & $1.86 \pm 1.23(1.40-2.33)$ & $0.957^{\mathrm{b}}$ & $1.77 \pm 1.03(1.51-2.04)$ & $1.82 \pm 1.40(1.24-2.39)$ & 0.873 \\
\hline DV TG & $-0.66 \pm 2.18(-1.24$ to -0.09$)$ & $0.05 \pm 0.72(-0.22$ to 0.33$)$ & $0.007^{\mathrm{b}}$ & $-0.53 \pm 2.13(-1.08$ to 0.02$)$ & $-0.18 \pm 0.92(-0.56$ to 0.20$)$ & $0.672^{\mathrm{b}}$ \\
\hline \multicolumn{7}{|l|}{ TC, $\mathrm{mmol} / \mathrm{l}$} \\
\hline Baseline & $5.00 \pm 0.88(4.76-5.23)$ & $4.93 \pm 1.02(4.54-5.32)$ & 0.346 & $4.96 \pm 0.92(4.72-5.19)$ & $5.04 \pm 0.97(4.64-5.44)$ & 0.707 \\
\hline After treatment & $4.80 \pm 0.78(4.59-5.00)$ & $4.55 \pm 0.79(4.24-4.84)$ & 0.154 & $4.73 \pm 0.83(4.52-4.95)$ & $4.67 \pm 0.69(4.39-4.96)$ & 0.759 \\
\hline DV TC & $-0.20 \pm 0.67(-0.38$ to -0.02$)$ & $-0.39 \pm 1.01(-0.77$ to 0.00$)$ & $0.531^{b}$ & $-0.22 \pm 0.69(-0.40$ to -0.05$)$ & $-0.37 \pm 1.04(-0.80$ to 0.06$)$ & $0.754^{\mathrm{b}}$ \\
\hline \multicolumn{7}{|l|}{$\mathrm{HDL}-\mathrm{C}, \mathrm{mmol} / \mathrm{l}$} \\
\hline Baseline & $1.06 \pm 0.35(0.96-1.15)$ & $1.14 \pm 0.33(1.02-1.27)$ & 0.684 & $1.09 \pm 0.32(1.01-1.17)$ & $1.07 \pm 0.40(0.91-1.23)$ & 0.791 \\
\hline After treatment & $1.13 \pm 0.36(1.04-1.23)$ & $1.12 \pm 0.42(0.96-1.28)$ & 0.881 & $1.11 \pm 0.36(1.02-1.21)$ & $1.18 \pm 0.44(0.99-1.36)$ & 0.495 \\
\hline DV HDL-C & $0.08 \pm 0.38(-0.02$ to 0.18$)$ & $-0.02 \pm 0.29(-0.13$ to 0.08$)$ & $0.048^{\mathrm{b}}$ & $0.02 \pm 0.35(-0.07$ to 0.11$)$ & $0.11 \pm 0.37(-0.05$ to 0.26$)$ & $0.438^{\mathrm{b}}$ \\
\hline
\end{tabular}

Data are given as means \pm SD with $95 \% \mathrm{CI}$ in parentheses. ${ }^{*} \mathrm{p}<0.05 .{ }^{\mathrm{a}} \mathrm{p}$ values represent the statistical difference between the AA and AC+CC $(\mathrm{GG}$ and $\mathrm{GT}+\mathrm{TT}$ ) genotype groups and were assessed by the two-sample $\mathrm{t}$ test. ${ }^{\mathrm{b}} \mathrm{p}$ values were determined by the Mann-Whitney test.

rs1470579 were not significantly different between the T2DM patients and the control group. However, the OR was 2.002 (95\% CI 1.170-3.426, p < 0.05) after adjustment for BMI, TG and LDL. We found that T2DM patients with the C allele of rs1470579 had higher FPG $(\mathrm{p}<0.05)$ and PPG $(\mathrm{p}<0.05)$ levels than those with the AA genotype. An association of polymorphism rs4402960 with T2DM has been reported in Caucasians such as Swedes [24], Danes [25] and French [21] as well as in Asians such as Japanese [26] and Chinese [27]. In our research, the frequency of T2DM occurrence was higher in mutated rs4402960 GT+TT carriers than in the GG genotype group ( $\mathrm{p}<0.05)$, and the OR was $1.879(95 \%$ CI 1.110
3.182, $\mathrm{p}<0.05)$ after adjustment for BMI, TG and LDL. We found that T2DM patients with the T allele had higher FPG $(p<0.01)$ and PPG $(p<0.05)$ levels than those with the GG genotype. Ruchat et al. [28] reported a strong association between the IGF2BP2 gene rs 4402960 polymorphism and glucose tolerance, such as FPG, glucose area under the curve and PPG. These two polymorphisms in the IGF2BP2 gene were also associated with pancreatic $\beta$-cell function [20]. All the evidence indicated that mutated IGF2BP2 gene carriers showed worse conditions in T2DM development.

IGF2BP2 belongs to the IGF2 mRNA-binding protein family and regulates its translation. IGF2 is a member of 
the insulin family of polypeptide growth factors, which plays an important role in the development, growth and stimulation of insulin action [29]. IGFBP homologs make a potential contribution to pancreatic development [30, 31]. IGF2BP2 gene variations are also associated with pancreatic $\beta$-cell function [20] and hyperglycemia [28]. The IGF2BP2 gene is located on chromosome 3q27.2. Polymorphisms rs1470579 and rs4402960 are in intron 2 of this gene. How the polymorphisms in this intron affect gene function should be further investigated. Possible mechanisms could be alternative splicing, microRNA or antisense mRNA transcription, etc. Other genes such as the insulin-sensitizing adipokine adiponectin (ADIPOQ) and protein phosphatase 1, regulatory subunit 2(PPP1R2), which are located in proximity to IGF2BP2, could also contribute to the regulation of insulin function [32].

TZD improved insulin sensitivity by inhibiting mitochondrial fuel oxidation and increasing glucose transport in skeletal muscle cells [33]. Because the IGF2BP2 gene showed an effect on T2DM development and insulin function and variations in this gene were associated with insulin sensitivity and glucose tolerance [28], we hypothesized that IGF2BP2 gene mutations could change the therapeutic efficacy of pioglitazone. In this case-control study, we found that T2DM patients with the IGF2BP2 gene rs1470579 $\mathrm{AC}+\mathrm{CC}$ genotypes showed lower pioglitazone effects on PPG ( $\mathrm{p}<0.05)$, TG $(\mathrm{p}<0.01)$ and HDL$\mathrm{C}(\mathrm{p}<0.05)$ concentrations than rs1470579 AA genotype carriers. The effect of pioglitazone on the PPG level was also lower in patients with the GT+TT genotypes of rs4402960 than in individuals with the GG genotype ( $\mathrm{p}<$ $0.05)$.
The relatively small sample size is one of the limitations of this study. Therefore, we calculated the power values for each analysis, which ranged from 75 to $95 \%$. We will need larger sample sizes for analysis in our future study. Another limitation is the lack of pioglitazone plasma concentration values. We selected CYP2C $8 * 1 * 1$ genotype individuals for pioglitazone testing to exclude the pharmacokinetic influences of pioglitazone [34, 35].

In summary, the genetic polymorphisms rs1470579 and rs4402960 of the IGF2BP2 gene were associated with the therapeutic efficacy of pioglitazone in Chinese T2DM patients. Patients with rs 1470579 polymorphism AC+CC genotypes or with rs4402960 polymorphism GT+TT genotypes appeared to experience a lower therapeutic efficacy of pioglitazone. However, the exact molecular mechanism needs to be elucidated in the future.

\section{Acknowledgements}

This study was supported by the National Natural Science Foundation of China (grant 81202596), the Specialized Research Fund for the Doctoral Program of Higher Education (20113420120006), the China Postdoctoral Science Foundation (2013M540508), Grants for Scientific Research of BSKY (XJ201021), Young Top-Notch Talent Support Programs from the Anhui Medical University (2012), the Anhui Province Nature Science Foundation in University (KJ2012Z158) and the Foundation for Key Teachers by the Anhui Medical University (2013).

\section{Disclosure Statement}

The authors have no potential conflicts of interest to disclose.

\section{References}

1 Whiting DR, Guariguata L, Weil C, Shaw J: IDF diabetes atlas: global estimates of the prevalence of diabetes for 2011 and 2030. Diabetes Res Clin Pract 2011;94:311-321.

2 Cornell S, Dorsey VJ: Diabetes pharmacotherapy in 2012: considerations in medication selection. Postgrad Med 2012;124:84-94.

-3 Matsuda A, Kuzuya T: Relationship between obesity and concordance rate for type 2 (noninsulin-dependent) diabetes mellitus among twins. Diabetes Res Clin Pract 1994;26:137143.

-4 Huang Q, Yang TL, Tang BS, Chen X, Huang $\mathrm{X}$, Luo $\mathrm{XH}$, et al: Two novel functional single nucleotide polymorphisms of $A D R B 3$ are associated with type 2 diabetes in the Chinese population. J Clin Endocrinol Metab 2013; 98:E1272-E1277.
5 Huang Q, Yin JY, Dai XP, Wu J, Chen X, Deng CS, et al: Association analysis of SLC30A8 rs13266634 and rs16889462 polymorphisms with type 2 diabetes mellitus and repaglinide response in Chinese patients. Eur J Clin Pharmacol 2010;66:1207-1215.

-6 Koster JC, Marshall BA, Ensor N, Corbett JA, Nichols CG: Targeted overactivity of $\beta$ cell $\mathrm{K}_{\text {ATP }}$ channels induces profound neonatal diabetes. Cell 2000;100:645-654.

7 Takeuchi F, Serizawa M, Yamamoto K, Fujisawa T, Nakashima E, Ohnaka K, et al: Confirmation of multiple risk loci and genetic impacts by a genome-wide association study of type 2 diabetes in the Japanese population. Diabetes 2009;58:1690-1699.

8 Omori S, Tanaka Y, Takahashi A, Hirose H, Kashiwagi A, Kaku K, et al: Association of
CDKAL1, IGF2BP2, CDKN2A/B, HHEX, SLC30A8, and KCNJ11 with susceptibility to type 2 diabetes in a Japanese population. Diabetes 2008;57:791-795.

9 Huang Q, Yin JY, Dai XP, Pei Q, Dong M Zhou ZG, et al: IGF2BP2 variations influence repaglinide response and risk of type 2 diabetes in Chinese population. Acta Pharmacol Sin 2010;31:709-717.

10 Christiansen J, Kolte AM, Hansen TO, Nielsen FC: IGF2 mRNA-binding protein 2: biological function and putative role in type 2 diabetes. J Mol Endocrinol 2009;43:187-195.

11 Zeggini E, Weedon MN, Lindgren CM, Frayling TM, Elliott KS, Lango H, et al: Replication of genome-wide association signals in UK samples reveals risk loci for type 2 diabetes. Science 2007;316:1336-1341. 
$\checkmark 12$ Groenewoud MJ, Dekker JM, Fritsche A, Reiling E, Nijpels G, Heine RJ, et al: Variants of CDKAL1 and IGF2BP2 affect first-phase insulin secretion during hyperglycaemic clamps. Diabetologia 2008;51:1659-1663.

13 Willson TM, Lambert MH, Kliewer SA: Peroxisome proliferator-activated receptor gamma and metabolic disease. Annu Rev Biochem 2001;70:341-367.

14 Zimmet P: Addressing the insulin resistance syndrome: a role for the thiazolidinediones. Trends Cardiovasc Med 2002;12:354-362.

15 Namvaran F, Azarpira N, Rahimi-Moghaddam P, Dabbaghmanesh MH: Polymorphism of peroxisome proliferator-activated receptor $\gamma($ PPAR $\gamma)$ Prol2Ala in the Iranian population: relation with insulin resistance and response to treatment with pioglitazone in type 2 diabetes. Eur J Pharmacol 2011;671:1-6.

-16 Makino H, Shimizu I, Murao S, Kondo S, Tabara Y, Fujiyama M, et al: A pilot study suggests that the $\mathrm{G} / \mathrm{G}$ genotype of resistin single nucleotide polymorphism at -420 may be an independent predictor of a reduction in fasting plasma glucose and insulin resistance by pioglitazone in type 2 diabetes. Endocr J 2009; 56:1049-1058.

17 Friedewald WT, Levy RI, Fredrickson DS: Estimation of the concentration of low-density lipoprotein cholesterol in plasma, without use of the preparative ultracentrifuge. Clin Chem 1972;18:499-502.

18 Duesing K, Fatemifar G, Charpentier G, Marre M, Tichet J, Hercberg S, et al: Evaluation of the association of IGF2BP2 variants with type 2 diabetes in French Caucasians. Diabetes 2008;57:1992-1996.

19 Horikawa Y, Miyake K, Yasuda K, Enya M, Hirota Y, Yamagata K, et al: Replication of genome-wide association studies of type $2 \mathrm{di}$ abetes susceptibility in Japan. J Clin Endocrinol Metab 2008;93:3136-3141.
$20 \mathrm{Wu}$ Y, Li H, Loos RJ, Yu Z, Ye X, Chen L, et al:Commonvariantsin $C D K A L 1, C D K N 2 A / B$, IGF2BP2, SLC30A8, and HHEX/IDE genes are associated with type 2 diabetes and impaired fasting glucose in a Chinese Han population. Diabetes 2008;57:2834-2842.

21 Cauchi S, Meyre D, Durand E, Proenca C, Marre M, Hadjadj S, et al: Post genome-wide association studies of novel genes associated with type 2 diabetes show gene-gene interaction and high predictive value. PLoS One 2008;3:e2031.

22 Nemr R, Echtay A, Dashti EA, Almawi AW, Al-Busaidi AS, Keleshian SH, et al: Strong association of common variants in the IGF2BP2 gene with type 2 diabetes in Lebanese Arabs. Diabetes Res Clin Pract 2012;96:225-229.

23 Mtiraoui N, Turki A, Nemr R, Echtay A, Izzidi I, Al-Zaben GS, et al: Contribution of common variants of ENPP1, IGF2BP2, KCNJ11, MLXIPL, PPAR $\gamma, S L C 30 A 8$ and TCF7L2 to the risk of type 2 diabetes in Lebanese and Tunisian Arabs. Diabetes Metab 2012;38:444-449.

24 Sjögren M, Lyssenko V, Jonsson A, Berglund G, Nilsson P, Groop L, et al: The search for putative unifying genetic factors for components of the metabolic syndrome. Diabetologia 2008;51:2242-2251.

25 Grarup N, Rose CS, Andersson EA, Andersen G, Nielsen AL, Albrechtsen A, et al: Studies of association of variants near the HHEX, $C D K N 2 A / B$, and IGF2BP2 genes with type 2 diabetes and impaired insulin release in 10,705 Danish subjects: validation and extension of genome-wide association studies. Diabetes 2007;56:3105-3111.

26 Iwata M, Maeda S, Kamura Y, Takano A, Kato $\mathrm{H}$, Murakami S, et al: Genetic risk score constructed using 14 susceptibility alleles for type 2 diabetes is associated with the early onset of diabetes and may predict the future requirement of insulin injections among Japanese individuals. Diabetes Care 2012;35:1763-1770.

27 Han X, Luo Y, Ren Q, Zhang X, Wang F, Sun $\mathrm{X}$, et al: Implication of genetic variants near SLC30A8, HHEX, CDKAL1, CDKN2A/B, IGF2BP2, FTO, TCF2, KCNQ1, and WFS1 in type 2 diabetes in a Chinese population. BMC Med Genet 2010;11:81.
28 Ruchat SM, Elks CE, Loos RJ, Vohl MC, Weisnagel SJ, Rankinen T, et al: Association between insulin secretion, insulin sensitivity and type 2 diabetes susceptibility variants identified in genome-wide association studies. Acta Diabetol 2009;46:217-226.

29 Scott LJ, Mohlke KL, Bonnycastle LL, Willer CJ, Li Y, Duren WL, et al: A genome-wide association study of type 2 diabetes in Finns detects multiple susceptibility variants. Science 2007;316:1341-1345.

30 Spagnoli FM, Brivanlou AH: The RNA-binding protein, Vg1RBP, is required for pancreatic fate specification. Dev Biol 2006;292:442456

- 31 Wagner M, Kunsch S, Duerschmied D, Beil M, Adler G, Mueller F, et al: Transgenic overexpression of the oncofetal RNA binding protein KOC leads to remodeling of the exocrine pancreas. Gastroenterology 2003;124:19011914.

32 Doria A, Patti ME, Kahn CR: The emerging genetic architecture of type 2 diabetes. Cell Metab 2008;8:186-200.

33 Brunmair B, Gras F, Neschen S, Roden M, Wagner L, Waldhausl W, et al: Direct thiazolidinedione action on isolated rat skeletal muscle fuel handling is independent of peroxisome proliferator-activated receptor- $\gamma$ mediated changes in gene expression. Diabetes 2001;50:2309-2315.

34 Daily EB, Aquilante CL: Cytochrome P450 2C8 pharmacogenetics: a review of clinical studies. Pharmacogenomics 2009;10:14891510.

-35 Jaakkola T, Laitila J, Neuvonen PJ, Backman JT: Pioglitazone is metabolised by CYP2C8 and CYP3A4 in vitro: potential for interactions with CYP2C8 inhibitors. Basic Clin Pharmacol Toxicol 2006;99:44-51. 


\section{Erratum}

In the article by Zhang LF, Pei Q, Yang GP, Zhao YC, Mu YF, Huang Q and Zhu YL, entitled 'The effect of IGF2BP2 gene polymorphisms on pioglitazone response in Chinese type 2 diabetes patients' [Pharmacology 2014;94:115-122, DOI: 10.1159/000363414], the following additional information needs to be added:

Qiong Huang and You-Ling Zhu contributed equally to this work.

The appropriate corresponding addresses are:

Prof. Qiong Huang

Institute of Clinical Pharmacology, Anhui Medical University

Key Laboratory of Anti-Inflammatory and Immune Medicine, Ministry of Education Hefei, Anhui 230032 (PR China)

E-Mail qionghuang@126.com

Prof. You-Ling Zhu

Department of Neurology, Hefei Binhu Hospital

Hefei First People's Hospital

Hefei, Anhui 230061 (PR China)

E-Mail zhuyoulinger@hotmail.com 